Palavras chave: Concentração de mercado Mercado internacional e PMVA Molduras

Histórico: Recebido 22/I2/201 I Aceito 17/07/2014

Keywords: Market concentration International market HAVP Molding

Correspondência: jaquelineheimann@yahoo.com.br
Jaqueline de Paula Heimann', Kelly Gonçalves', André Ramos Dresch', Joao Carlos Garzel Leodoro da Silva'

\section{CONCENTRAÇÃO DE MERCADO DE MOLDURAS (FRAME) IMPORTADAS PELOS ESTADOS UNIDOS, PERÍODO DE 2005 A 2009.}

RESUMO: O comércio internacional de produtos florestais entre diferentes nações vem crescendo ao longo dos anos, as molduras de tipo frame, tem se destacado entre os produtos de maior valor agregado. No presente estudo, objetivou-se analisar as importações de molduras (frame) pelos EUA, no período de 2005 a 2009. Para tanto, fezse uso de índices de concentração, mostrando o comportamento do mercado examinado. Os índices escolhidos para este trabalho foram: razão de concentração dos quatro e oito países com maior valor de importação, o índice de Herfindahl-Hirschman e o Índice de Gini. Os resultados apontam para um mercado dominado, altamente concentrado, com cerca de $94 \%$ de concentração nos 4 principais países exportadores e $97 \%$ concentrado nos oito principais. É possível concluir que a China é o principal exportador de molduras do tipo frame para o mercado estadunidense, detendo, aproximadamente, $70 \%$ do total das importações de frame dos EUA.

\section{CONCENTRATION OF FRAMES IMPORTED BY THE UNITED STATES, PERIOD OF 2005 TO 2009.}

ABSTRACT: This paper aims to analyze the U.S imports of frames between 2005 and 2009. Concentration indexes were used to characterize the behavior of the studied market. The indices chosen for this work were: concentration ratio of the four and the eight countries with the highest import, rate of market concentration of the same four and eight major countries, the Herfindahl-Hirschman and Gini Index. All the results indicate to a dominated market, highly concentrated, and with $94 \%$ of the market centered on four main exporting countries and $97 \%$ concentrated in the top eight. Also, it is possible to conclude that China is the main exporter of frames for the U.S. market, holding approximately $70 \%$ of total frames imports. 


\section{INTRODUÇÃO}

Observando-se o contexto atual, é possível verificar que a atividade florestal se intensificou em todo o mundo, o que é confirmado, por meio do crescente comércio de produtos florestais entre diferentes nações e, também, pelo renovado interesse de diversas organizações pelas florestas (NOCE et al., 2005).

O reprocessamento da madeira serrada, com enfoque na agregação de valor ao produto primário, é algo que a maioria das empresas brasileiras vem buscando nos últimos anos e tem se constituído em uma tendência, sendo os produtos mais representativos, tratando-se de produtos de maior valor agregado, os blocks, blanks, molduras, painel colado lateral, pisos, pré-cortados, componentes estruturais e outros (SILVA, 20I2).

Um dos produtos que apresenta alto valor agregado é a moldura, que demonstra destaque nas exportações dos produtos de origem florestal, apesar de ser pouco conhecido e utilizado no mercado interno (ASSOCIAÇÃO BRASILEIRA DA INDÚSTRIA DE MADEIRA PROCESSADA MECANICAMENTE $A B I M C l, 20 I I)$.

Apesar de não se ter estatísticas precisas, a estimativa é a de que os valores totais das molduras de pinus exportadas pelo Brasil cheguem a 400 milhões de dólares por ano. Por sua característica de produto elaborado, o destino das molduras de pinus é quase que exclusivamente a exportação.

No entanto, como todos os produtos dirigidos ao mercado externo, a exportação de molduras sofre com aspectos econômicos como a valorização do real frente ao dólar, concorrência internacional e preço da matéria-prima. As estimativas dos produtores quanto aos volumes produzidos de molduras, a partir de madeiras tropicais são equivalentes a $\mathbf{3 0 0}$ mil metros cúbicos por ano (MOLDURAS..., 2005).

Ao tratarmos de molduras artísticas (frame), além de Estados Unidos e Canadá, a Europa se torna grande consumidora do produto brasileiro. Do total produzido no Brasil, desse tipo de moldura, $80 \%$ é exportado (MOLDURAS..., 2008).

As molduras para o segmento artístico (quadros, porta retratos, espelhos, móveis, chassis em geral) são fabricadas a partir de espécies de baixa densidade, como: marupá, virola, parapará (caixeta) e um pouco de eucalipto. São madeiras de baixa resistência e baixa densidade, por isso são mais baratas, leves, fáceis de secar e de usinar (MOLDURAS..., 2005).
Deacordo com Noce etal. (2005) a concentração industrial é um dos principais determinantes estruturais da competição, a concentração tem influência sobre as estratégias adotadas pelas firmas participantes, a economia de escala, $\circ$ tamanho e $\circ$ crescimento do mercado, além das condições de entrada.

Diante do exposto, objetivou-se neste estudo, avaliar a concentração das importações americanas do setor de molduras (frame) entre os anos de 2005 a 2009. Para tanto, o artigo se propõe a determinar as Razões de concentração (CR4 e CR8), o Índice de Gini e o Índice de Herfindahl-Hirschman; identificar os maiores exportadores de molduras frame aos Estados Unidos; estabelecer o nível de concentração desse mercado e indicar o tipo de estrutura de concentração encontrado no mercado de importação estadunidense de frame.

\section{METODOLOGIA}

\section{Referencial teórico}

Segundo Silva (20I2), molduras são perfis obtidos a partir do reprocessamento da madeira serrada ou dos blocks e blanks. O maior consumidor de molduras é o segmento da construção civil, tanto no âmbito do mercado interno como internacional.

Exemplos de aplicação prática desses produtos é em rodapés (utilizado nas junções entre o piso e parede), a meia-cana, meia-lua e cordão, onde as molduras assumem formatos e medidas variadas, atendendo às mais diversas necessidades, voltadas, principalmente, para o mercado externo.

A produção brasileira de molduras de Pinus está praticamente toda orientada para o mercado externo, sendo que as molduras de madeiras tropicais também possuem relevância e, de forma similar ao Pinus, estão orientadas para o mercado internacional.

Faz-se necessário aqui, demonstrar a diferença entre os tipos de molduras encontradas no mercado. Existem as molduras molding, que são utilizadas na construção civil, tais como: (i) rodapés; (ii) meia-cana; (iii) meia-lua e (iv) cordão e tem grande participação na exportação brasileira. Existem ainda as molduras do tipo frame, que são utilizadas na área artística, como: (i) quadros; (ii) porta-retratos; (iii) espelhos (MOLDURAS..., 2008), sendo este último o objeto do presente estudo.

Ao tratarmos de molduras artísticas (frame), além de Estados Unidos e Canadá, a Europa se torna grande consumidora do produto brasileiro. Do total produzido no Brasil, desse tipo de moldura, $80 \%$ é exportado (MOLDURAS..., 2008). 
Em estudos de organizações industriais, tornase mais comum estudar a concentração para aproximarse da estrutura de mercado (RESENDE, 1994).

Em um sentido amplo, concentração significa acumulação de certos atributos econômicos (tais como renda, riqueza, produção, etc.) por correspondentes unidades de controle (indivíduos, firmas, estabelecimentos industriais), e tem-se revelado um conceito extremamente útil em vários campos de investigação econômica, tais como distribuição de renda e estrutura industrial (BRAGA; MASCOLO, 1982).

Soares et al. (2006) afirmam que o termo concentração industrial é bastante utilizado nos estudos de organização industrial, por ser um dos itens mais importantes em estruturas de mercados, ressaltando que a mesma é crucial na classificação de um mercado segundo sua estrutura.

Assim, a concentração industrial torna-se um dos principais determinantes estruturais da competição, podendo afetar as estratégias adotadas pelas firmas participantes, a economia de escala, o tamanho e o crescimento do mercado, além das condições de entrada (NOCE et al., 2005), sendo que em níveis elevados, ela pode prejudicar a alocação eficiente de recursos (KON, 1999).

Segundo Pindyck e Rubinfeld (2005) as decisões de preço, investimento e níveis de produção de uma empresa têm forte dependência da estrutura de mercado em que ela está inserida e com o comportamento apresentado por seus concorrentes.

Segundo Kon (1999), as teorias neoclássicas sugerem que uma indústria concentrada, ou seja, com um número pequeno de grandes empresas, são prejudiciais à competição, pelo fato de estas agirem de forma interdependente uma da outra, tanto quanto a preço como produção. $\mathrm{O}$ mesmo autor aborda o fato de que essa concentração de mercado pode ser analisada de uma forma estática, em um determinado ponto no tempo, ou na forma dinâmica, observando o crescimento ou decréscimo no tempo.

Um oligopólio corresponde a uma estrutura de mercado de concorrência imperfeita, caracterizada pelo fato do mercado ser dominado por um número reduzido de empresas produtoras pelo que, uma única empresa tem poder para influenciar o preço do bem. Num oligopólio, os bens produzidos podem ser homogêneos ou apresentar alguma diferenciação e apresentam como característica importante o fato de estarem em setores com fortes barreiras à entrada de novas empresas, sejam elas os elevados custos de entrada, as limitações legais, ou outras (NUNES, 20I0).
De acordo com Pindyck e Rubinfeld (2005), monopólio é um mercado em que há apenas um vendedor e muitos compradores, condição completamente oposta à concorrência perfeita, em que há muitos vendedores e também muitos compradores. Os autores ainda afirmam que uma condição de monopólio puro é bastante rara, porém existem mercados em que apenas algumas empresas encontram-se concorrendo entre si, essas empresas podem se unir e, assim, cobrar preços mais elevados por seus produtos, obtendo o poder de monopólio.

Concorrência perfeita é a mais conhecida das estruturas de mercado. De forma sucinta, a concorrência perfeita é determinada por um número grande de empresas que oferecem produtos homogêneos, ou seja, sem diferenciação significativa, são tomadoras de preço, e não existem barreiras à entrada de novos participantes no setor (MELO; TAVARES, 2009).

\section{Referencial analítico}

No presente estudo, utilizou-se $\circ$ índice de Herfindahl-Hirschman e Coeficiente de Gini e, ainda, a título de comparação de resultados, para uma melhor percepção de mercado do produto estudado, foram determinadas as razões de concentração CR4 (grupo dos quatro principais países exportadores), CR8 (grupo dos oito principais países exportadores). Os índices foram escolhidos com base nos trabalhos de Santos e Santana (2003) "Concentração e poder de mercado das empresas de artefatos de madeira do Estado do Pará", Noce et al. (2005) "Concentração das Exportações no Mercado Internacional de Madeira Serrada” e Paula e Cardoso (2009) "Mapeamento da concentração regional do setor paranaense de celulose e papel - Parte I".

Para Razão de Concentração, este estudo utilizou-se dos quatro e oito países com maior valor de exportação de molduras do tipo frame para os Estados Unidos da América ( $\mathrm{N}=4$ e $\mathrm{N}=8)$. Os cálculos foram realizados conforme a equação $(\mathrm{I})$, onde $\mathrm{C}_{\mathrm{N}}=\mathrm{a}$ razão de concentração das $\mathrm{N}$ empresas e $\mathrm{Q}_{\mathrm{i}}=$ valor de participação do país i.

$$
\mathrm{CN}=\sum_{\mathrm{i}=1}^{\mathrm{N}}\left[\frac{\mathrm{Qi}}{\sum_{\mathrm{i}=1}^{\mathrm{M}} \mathrm{Qi}}\right]
$$

Medeiros e Reis (1997) estabelecem um quadro de padrões de concentração que classificam os mercados 
de altamente concentrado a claramente atomístico, conforme apresentado na tabela I a seguir.

TABELA1 Classificação dos mercados segundo a razão de concentração.

TABLE 1 Market classification according to the concentration ratio.

\begin{tabular}{lll}
\hline Níveis de Mercado & CR4 & CR8 \\
\hline Altamente concentrado & $\mathrm{i}>75 \%$ & $\mathrm{i}>90 \%$ \\
Alta concentração & $65 \%<\mathrm{i}<75 \%$ & $85 \%<\mathrm{i}<90 \%$ \\
Concentração moderada & $50 \%<\mathrm{i}<65 \%$ & $70 \%<\mathrm{i}<85 \%$ \\
Baixa concentração & $35 \%<\mathrm{i}<50 \%$ & $45 \%<\mathrm{i}<70 \%$ \\
Ausência de concentração & $\mathrm{i}<35 \%$ & $\mathrm{i}<45 \%$ \\
Claramente atomístico & $\mathrm{i}=2 \%$ &
\end{tabular}

Fonte: Medeiros e Reis (1997).

O Índice de Herfindahl-Hirschman é definido pela soma dos quadrados da participação de cada nação no mercado internacional e considera a participação de todas as nações, de forma que aumenta à medida que intensifica a concentração. $\mathrm{Na}$ equação 2 , ilustra-se o procedimento de cálculo, onde $\mathrm{H}=$ índice de HerfindahlHirschman e $P_{i}=$ participação percentual da nação ${ }_{i}$ no total das exportações.

$\mathrm{IHH}=\sum_{i=1}^{n} P_{i}^{2}$

O valor máximo de I, representa a situação de monopólio, ou seja, um único país detendo todo o mercado, enquanto o valor mínimo de 0 representa a concorrência perfeita, como mostra o quadro a seguir (Tabela 2), apresentado por Silva (2003).

TABELA 2 Classificação do índice de Herfindahl-Hirschman. TABLE 2 Classification of the Herfindahl-Hirschman Index.

\begin{tabular}{ll}
\hline $\mathrm{H} 1$ tende a 0 & Mercado tende a concorrência perfeita \\
\hline $\mathrm{H} 1=1$ & Monopólio \\
$\mathrm{H} 1<0,1$ & Mercado altamente competitivo \\
$\mathrm{H} 1>0,18$ & Mercado altamente concentrado \\
\hline
\end{tabular}

Fonte: Silva (2003).

De acordo com Soares et al. (2006), o coeficiente de Gini pode ser entendido como uma medida capaz de indicar a extensão na qual as firmas em uma indústria têm tamanhos desiguais. Nesse caso, as firmas seriam representados pelos países com suas diferentes participações no mercado estadunidense de importações de frame. Para Gonçalves e Souza (1993) e Leite e Santana (2000), o Coeficiente de Gini representa mais uma medida de desigualdade do que de concentração.
De acordo com Resende (1994), o Índice de Gini (3) assume valores entre "zero" (ausência de concentração/igualdade absoluta entre todos os componentes do universo examinado) e "I" (concentração absoluta/desigualdade total). Para efeito de cálculo do Índice de Gini, utiliza-se a equação abaixo onde $\mathrm{G}=$ índice de Gini, $\mathrm{n}$ = número de países, $\mathrm{C}_{\mathrm{ij}}=$ participação acumulativa no consumo em ordem crescente e $\mathrm{Ci}=$ participação da fábrica i.

$\mathrm{G}=1-\sum_{\mathrm{i}=1}^{\mathrm{n}}(\mathrm{Cij}+\mathrm{Ci})$

Gonçalves e Souza (1993) relatam que quanto mais próximo da unidade (um), maior será a concentração, e quanto mais próximo de zero, melhor distribuição dentro do mercado. Os autores ainda afirmam que "em função de sua construção, o Índice de Gini será sempre uma subestimação do índice de desigualdade real".

Em termos de convenção, pode-se classificar o nível de concentração de um mercado, segundo os valores do Índice de Gini, da maneira proposta por Noce et al. (2005) apresentado na Tabela 3.

TABELA 3 Classificação da desigualdade pelo índice de Gini. TABLE 3 Classification of inequality by the Gini index.

\begin{tabular}{ll}
\hline Valor do Índice de Gini & Desigualdade do Mercado \\
\hline $0,101-0,250$ & Nula a fraca \\
$0,251-0,500$ & Fraca a média \\
$0,501-0,700$ & Média a forte \\
$0,701-0,900$ & Forte a muito forte \\
$0,901-1,000$ & Muito forte a absoluta \\
\hline
\end{tabular}

Fonte: Noce et al. (2005).

\section{Banco de dados}

Os dados utilizados no presente estudo foram obtidos na base de dados da Divisão de Estatísticas das Nações Unidas - Comtrade (20I3), sendo selecionados dados de importação de molduras (frame) dos Estados Unidos, entre anos de 2005 a 2009, obtendo-se todos os valores $\mathrm{FOB}$ (preço de venda da mercadoria acrescido de todas as despesas que o exportador faz até colocá-lo a bordo) de importação deste país.

\section{RESULTADOS E DISCUSSÃO}

Para melhor compreensão dos resultados, os mesmos foram apresentados em forma de percentual, 
facilitando, assim, a visualização da concentração de molduras (frame) importadas pelo mercado estadunidense.

Os dados do Comtrade coletados apontam como maiores exportadores de molduras, do tipo frame, destinadas aos EUA, no período estudado, a China, Tailândia, Indonésia e México (Tabela 4).
Já, os outros países que compuseram os oito principais exportadores mostraram uma alta variabilidade inclusive pela pequena participação dos mesmos, estando no início o Canadá, Brasil e Itália dentre estes e, após, saem desse ranking, depois saindo com a entrada Índia, Vietnã e Polônia.

TABELA 4 Países com maior exportação de molduras do tipo frame para EUA, no período estudado, em relação ao valor FOB exportado.

TABLE 4 Countries with larger export of frame for the U.S. during the studied period, compared to the FOB value exported.

\begin{tabular}{|c|c|c|c|c|c|c|c|c|c|}
\hline \multicolumn{2}{|c|}{2005} & \multicolumn{2}{|c|}{2006} & \multicolumn{2}{|c|}{2007} & \multicolumn{2}{|c|}{2008} & \multicolumn{2}{|c|}{2009} \\
\hline China & $54 \%$ & China & $57 \%$ & China & $62 \%$ & China & $67 \%$ & China & $66 \%$ \\
\hline Tailândia & $17 \%$ & Tailândia & $18 \%$ & Tailândia & $14 \%$ & Tailândia & $12 \%$ & Tailândia & $14 \%$ \\
\hline México & $12 \%$ & Indonésia & $11 \%$ & Indonésia & $12 \%$ & Indonésia & $9 \%$ & Indonésia & $10 \%$ \\
\hline Indonésia & $10 \%$ & México & $8 \%$ & México & $7 \%$ & México & $6 \%$ & México & $5 \%$ \\
\hline Canadá & $1 \%$ & Canadá & $1 \%$ & Canadá & $1 \%$ & Polônia & $1 \%$ & Polônia & $1 \%$ \\
\hline Malásia & $1 \%$ & Índia & $1 \%$ & Malásia & $1 \%$ & Hong-Kong & $1 \%$ & Índia & $1 \%$ \\
\hline Brasil & $1 \%$ & Malásia & $1 \%$ & Índia & $1 \%$ & Índia & $1 \%$ & Vietnã & $1 \%$ \\
\hline Itália & $1 \%$ & Itália & $1 \%$ & Itália & $1 \%$ & Malásia & $1 \%$ & Malásia & $1 \%$ \\
\hline & & Brasil $\left(15^{\circ}\right)$ & $0,1 \%$ & Brasil $\left(11^{\circ}\right)$ & $0,4 \%$ & Brasil $\left(16^{\circ}\right)$ & $0,1 \%$ & Brasil $\left(14^{\circ}\right)$ & $0,1 \%$ \\
\hline
\end{tabular}

Fonte: elaborado pelos autores.

O Brasil é um país com pequena participação no mercado americano de molduras frame com uma participação máxima de 1\% em 2005 (Tabela 4), figurando, naquele ano, entre os oito principais países exportadores desse produto. Porém, houve uma queda significativa tanto em sua a participação, chegando a apenas $0,1 \%$ nos anos seguintes. Assim, torna-se do necessário que as empresas adotem novas estratégias tanto de mercado como de produção, verificando as exigências existente no mercado americano para recuperarem a participação existente anteriormente.

Importante também é verificar o nível das políticas públicas visto que estas, obviamente, estão fora do nível de influência das empresas e, portanto, devem ser adequadas para a melhoria da competitividade empresarial.

A China (Tabela 4) foi sempre o principal exportador desse tipo de moldura para os Estados Unidos com uma participação crescente, saindo de uma participação de 54\% em 2005, para 64\% em 2009, evidenciando que há um grande poder por parte das empresas desse país no mercado exportador desses produtos nos Estados Unidos.

Também, durante todo o período, a Tailândia foi o segundo país no mercado importador americano, porém com uma leve queda de $17 \%$ para $14 \%$ entre o período inicial e final, enquanto a Indonésia, a partir de 2006, tornou-se o terceiro maior exportador, enquanto o México compôs o grupo dos 4 maiores exportadores com uma participação em 2009 de 5\%.
No que diz respeito à China, Carvalho e Catermol (2009) afirmam que esse país é um dos maiores parceiros comerciais dos EUA e que a economia de ambos tem grande interdependência. Adicionalmente, os mesmos pesquisadores ressaltam, que os EUA têm importado grandes quantidades de produtos da China, enquanto que esta importa bens de capital, grãos e insumos escassos no país.

As razões encontradas tanto para os quatro países quanto para os oito países principais exportadores de molduras (frame) foram, na média, do período estudado de $94 \%$ e $97 \%$ (Tabela 5), respectivamente, e durante todo o período de análise o nível de concentração desses indicadores não apresentaram variação. $O$ que se verifica, entre tanto é que houve um reposicionamento na participação como citado anteriormente.

TABELA 5 Resultados dos índices CR4, CR8, HHI e Coeficiente de Gini.

TABLE 5 CR4, CR8, HHI, and Gini Index, results.

\begin{tabular}{lllll}
\hline Ano & CR4 & CR8 & IHH & Gini \\
\hline 2005 & $93 \%$ & $96 \%$ & 0,344 & 0,937 \\
2006 & $94 \%$ & $97 \%$ & 0,377 & 0,945 \\
2007 & $95 \%$ & $97 \%$ & 0,422 & 0,938 \\
2008 & $94 \%$ & $97 \%$ & 0,470 & 0,943 \\
2009 & $94 \%$ & $98 \%$ & 0,471 & 0,940 \\
média & $94 \%$ & $97 \%$ & 0,417 & 0,94 \\
\hline
\end{tabular}

Fonte: elaborado pelos autores. 
Em relação aos quatro principais exportadores, a China aumentou seu market share, enquanto os outros três principais países tiveram a sua participação reduzida. Ou seja, a China conseguiu aumentar sua participação com um ganho dos mercados dos seus principais concorrentes.

Assim, esse mercado, exportador de molduras tipo frame para os Estados Unidos, classifica-se como de alta concentração, configurando-se em um oligopólio e de alta dificuldade para que outros países possam aumentar sua concorrência.

Já, o índice de Herfindahl-Hirschman calculado apresentou como resultado total médio do período o valor de 0,4l7 indicando também um mercado altamente concentrado e com um aumento na mesma, visto que esse índice teve, durante o período analisado um aumento em seu valor.

Ao mesmo tempo, o Índice de Gini apresentou um valor médio de 0,94 , o que, segundo o proposto por Gonçalves e Souza (1993), Leite e Santana (2000) e Noce et al. (2005) classificam o mercado como sendo de desigualdade forte a absoluta sem mudanças significativas na mesma, durante o período de análise.

Pinho e Avellar (2002), analisando as barreiras à entrada de novas indústrias no setor de papel e celulose, concluem que, em mercados mais concentrados, existem barreiras vinculadas a economias de escala. Fato este que pode explicar o domínio da China no mercado de exportação de molduras frame para os EUA.

Conforme Pindyck e Rubinfeld (2005), as decisões de preço têm forte dependência da estrutura de mercado em que essa empresa está inserida e, com o comportamento apresentado por seus concorrentes, é possível inferir que os preços, nesse setor, são ditados pela líder de mercado, China.

\section{CONCLUSÕES}

O mercado americano de importação de molduras tipo frame apresenta-se altamente concentrado, caracterizando-se assim como um oligopólio, tenda a China como o principal exportador .

Evidenciando-se, ainda, seu poder dentro das importações americanas desse produto, a China aumentou seu market share no período analisado em cima dos seus principais concorrentes que perderam participação, confirmando o alto poder da China e de suas empresas.

A alta concentração está bem evidenciada nos resultados dos índices analisados onde todos apresentaram esse poder de concentração e de desigualdade, com forte tendência à competição oligopolista, tendendo à proximidade com competição monopolística.

Sa há o desejo de empresas de outros países em competir nesse mercado, há a necessidade de novas estratégias para enfrentarem o poder apresentado, principalmente pela China.

As empresas brasileiras de moldura tipo frame, além de participarem com um percentual muito pequeno no mercado americano importador, no início do período, ainda não o mantiveram, tendo uma alta redução nessa participação, indicando uma falta de competitividade de suas empresas.

Não se pode concluir se essa falta de competitividade, foi por fatores internos à empresa ou externos à mesma, visto não ter sido este o objeto de estudo.

É preciso, entretanto, a adoção de uma postura mais competitiva por parte do Brasil de suas empresas, uma vez que agregar valor aos produtos madeireiros aumenta a rentabilidade, possibilita absorção de novas tecnologias, aumenta a capacitação técnica humana, além de ampliar a matriz de produtos e operações industriais.

\section{REFERÊNCIAS}

ASSOCIAÇÃO BRASILEIRA DA INDÚSTRIA DE MADEIRA PROCESSADA MECANICAMENTE. Estudo setorial 2009, ano base 2008. Disponível em: <http://www. abinci.com.br $>$. Acesso em: I3 maio 20 I I.

BRAGA, C. H.; MASCOLO, J. L. Mensuração da concentração industrial no Brasil. Pesquisa e Planejamento Econômico, Rio de Janeiro, v. I2, n. 2, p. 40I, ago. 1982.

CARVALHO, C.; CATERMOL, F. As relações econômicas entre China e EUA: resgate histórico e implicações. Revista do BNDES, Rio de Janeiro, v. 16, n. 3I, p. 2I5-252, 2009. Disponível em: <http://www.bndes.gov.br/SiteBNDES/ export/sites/default/bndes pt/Galerias/Arquivos/ conhecimento/revista/rev3108.pdf $>$. Acesso em: 2 jun. 2011 .

COMTRADE. Disponível em: <http://comtrade.un.org/>. Acesso em: 10 mar. 2013.

GONÇALVES, J. S.; SOUZA, S. A. M. Produção de alimentos e concentração fundiária: o caso do feijão em Itaberá, SP, no período de 1968-88. Agricultura em São Paulo, São Paulo, v. 40, n. I, p. 139-155, 1993. Disponível em: <ftp:// ftp.sp.gov.br/ftpiea/asp8-0193.pdf >. Acesso em: 26 abr. 2011 .

KON, A. Economia industrial. São Paulo: Nobel, 1999. 56 p. Disponível em: <http://books.google.com.br/s?hl=ptBR $\&|r=\& i d=v Y g X X 5 G K b m 8 C \& o i=f n d \& p g=P A| I \& d q=K O$ $\mathrm{N},+\mathrm{A} .+$ Economia + Industrial. \&ots $=09 \mathrm{mElsPBCE \& sig}=\mathrm{L}$ A IOLjCW3yZ2VtgkEMCabhtyWk\#v= snippet\& $q=$ conce $n$ trada\& $=$ false $>$. Acesso em: 22 jun. 2010. 
LEITE, A. L. S.; SANTANA, E. A. Concentração e desempenho competitivo no complexo industrial de papel e celulose. Episteme, Tubarão, v. 6/7, n. 19/20, p. 73-91, 2000.

MEDEIROS, N. H.; REIS, S. V. dos. A Concentração industrial na cadeia alimentar da soja. In: CONGRESSO BRASILEIRO DA SOBER, 37., 1999, Foz do Iguaçu. Anais... Brasília: SOBER, 1997. p. I-I5.

MELO, E. S.; TAVARES, J. M. Índices de concentração industrial em Minas Gerais: uma análise setorial: 2005-2007. Reuna, Belo Horizonte, v. I4, n. I, p. I I-27, 2009.

MOLDURAS: avaliação do produto com alto valor agregado. Revista Referência, Curitiba, ano 7, n. 44, p. 12-20, maio 2005.

MOLDURAS: avaliação sobre o momento econômico. Revista Referência, Curitiba, ano 8, n. 44, maio 2008. Disponível em: <http://www.revistareferencia. com.br/index2.php?principal=ver_conteudo. php\&uid $=3$ I0\&edicao2 $=44>$. Acesso em: 16 maio $201 \mathrm{I}$.

NOCE, R.; SILVA, M. L. da; CARVALHO, R. M. M. A.; SOARES, T. S. Concentração das exportações no mercado internacional de madeira serrada. Revista Árvore, Viçosa, v. 29 , n. 3, p. $431-437,2005$.

NUNES, P. Conceito de oligopólio. Disponível em: < http:// www.knoow.net/cienceconempr/economia/oligopolio. htm >. Acesso em: 6 jun. 2010.

PAULA, A. de F. Q. de; CARDOSO, G. da S. Mapeamento da concentração regional do setor paranaense de celulose e papel: parte I. São Paulo: SENAI, 2009.
PINDYCK, R. S.; RUBINFELD, D. L. Microeconomia. 6. ed. São Paulo: Prentice Hall, 2005.

PINHO, M.; AVELLAR, A. P. M. Economia de escala, barreiras à entrada e concentração na indústria de celulose e papel. In: ENCONTRO NACIONAL DE ENGENHARIA DE PRODUÇÃO, 22., 2002, Curitiba. Anais... Curitiba: UFPR, 2002. I CD-ROM.

RESENDE, M. Medidas de concentração industrial: uma resenha. Análise Econômica, Rio de Janeiro, ano II, p. 24-33, 1994.

SANTOS, M. A. S. dos; SANTANA, A. C. de. Concentração e poder de mercado das empresas de artefatos de madeira do Estado do Pará. In: ENCONTRO NACIONAL DE ENGENHARIA DE PRODUÇÃO, 23., 2003, Ouro Preto. Anais... Ouro Preto: UFOP, 2003. I CD-ROM.

SILVA, J. de C. Madeira de eucalipto: desafios e oportunidades. In: CONGRESSO FLORESTAL PARANAENSE, 4., 2012, Curitiba. Anais... Curitiba: APRE, 2012. Disponível em: $<$ http://malinovski.com.br/CongressoFlorestal/Arquivos HTML/2-Palestras.htm >. Acesso em: 21 abr. 2013.

SILVA, Z. A. G. P. da G. Análise econômica da concentração no uso de madeira tropical pelo setor de marcenarias de Rio Branco, Estado do Acre, 1996. Scientia Forestalis, Piracicaba, n. 6, p. 48-58, dez. 2003. Disponível em: <http://www.ipef.br/publicacoes/scientia/nr64/cap04. pdf $>$. Acesso em: 21 jul. 2010.

SOARES, T. S.; NISHI, M. H.; OLIVEIRA, P. R. S. de; SILVA, M. L. de. Concentração no consumo de madeira e estrutura de mercado do setor moveleiro do município de Ubá, MG. Revista Científica Eletrônica de Engenharia Florestal, São Paulo, ano 4, n. 7, p. I-10, fev. 2006. 